\title{
Michel Brix, Sainte-Beuve et la bataille d'"Hernani"
}

\section{Annarosa Poli}

\section{(2) OpenEdition}

\section{Journals}

\section{Edizione digitale}

URL: http://journals.openedition.org/studifrancesi/6028

DOI: ERREUR PDO dans /localdata/www-bin/Core/Core/Db/Db.class.php L.34 : SQLSTATE[HY000]

[2006] MySQL server has gone away

ISSN: 2421-5856

\section{Editore}

Rosenberg \& Sellier

\section{Edizione cartacea}

Data di pubblicazione: 1 mai 2011

Paginazione: 191

ISSN: 0039-2944

\section{Notizia bibliografica digitale}

Annarosa Poli, «Michel Brix, Sainte-Beuve et la bataille d"'Hernani"», Studi Francesi [Online], 163 (LV | I) | 2011, online dal 30 novembre 2015, consultato il 08 janvier 2021. URL: http://

journals.openedition.org/studifrancesi/6028 ; DOI: https://doi.org/10.4000/studifrancesi.6028

Questo documento è stato generato automaticamente il 8 janvier 2021.

\section{(c) (i) (9)}

Studi Francesi è distribuita con Licenza Creative Commons Attribuzione - Non commerciale - Non opere derivate 4.0 Internazionale. 


\title{
Michel Brix, Sainte-Beuve et la bataille d'Hernani"
}

\author{
Annarosa Poli
}

\section{NOTIZIA}

MICHEL BRIX, Sainte-Beuve et la bataille d'“Hernani”, in «Les Lettres Romanes», 2009,

t. LXIII, $\mathrm{n}^{\circ} 1$ e 2 , pp. 41-51.

1 La battaglia di Hernani costituisce un momento fondamentale nell'itinerario intellettuale e critico di Sainte-Beuve. Iniziano allora i primi dissensi tra Hugo e il critico che da tempo esprimeva le sue riserve sui drammi di quello che veniva ormai definito il "padre dei romantici".

2 Per Sainte-Beuve, Hernani è un dramma troppo lontano dalla realtà e dalla verità umana. Queste opinioni non le aveva mai espresse in un articolo, ma nella sua Corrispondenza e nella prefazione delle Consolations del 1829. Anche nel Cenacolo romantico si cominciavano a verificare degli screzi con la rottura tra Hugo e Vigny. Non si deve neppure dimenticare che non tutti si erano schierati dalla parte di Hugo. Così Balzac, che non aveva mai fatto parte del Cenacolo de «La Muse française», fece sentire una voce discorde in due articoli del «Feuilleton des journaux politiques», del 24 marzo e 7 aprile 1830. Il romanziere ironizzava su questa "arte nuova" opposta alla tradizione, poiché in realtà conservava "les poncifs et les ressorts" del passato, compresa la tragedia classica.

3 Era stato lo stesso Hugo a diffondere e a far diffondere l'idea di una rivoluzione letteraria, in rottura definitiva con il passato. In questi anni il dramma classico continuava a furoreggiare a teatro con il grande interprete Talma, così come la grande Rachel al Théâtre-Français e all'estero continuava a rappresentare Corneille.

4 Un membro del Cenacolo, Alexandre Soumet, aveva scritto tre tragedie classiche, Clytemnestre (1822), Saul (1822), Cléopatre (1824). Lo stesso Vigny presenta il suo More de Venise come una "tragédie" tradotta da Shakespeare "en vers français". 
È noto che, qualche settimana dopo l'insuccesso dei Burgraves (1843) di Ponsard, nel teatro dell'Odéon, il pubblico applaude con entusiasmo la Lucrèce dello stesso autore, una tragedia classica.

I romantici avevano basato la loro crociata drammatica rivendicando la modernità delle loro opere, contraria a riproporre i miti antichi troppo lontani dai contemporanei. Tuttavia non riuscirono ad eliminare tragedie ispirate dalla letteratura classica. Del resto, e questo ci pare il grande interesse dell'articolo di M. Brix, già nel Settecento con Voltaire, Diderot e Beaumarchais si era avvertita l'esigenza di adattare la tragedia alle esigenze dei contemporanei, creando le condizioni necessarie perché il patetico nascesse dalla realtà del tempo. I principi e gli dei dovrebbero essere sostituiti dai borghesi parigini. Il dramma borghese infatti si propone come una forma teatrale nuova con la sostituzione dei grandi personaggi della storia, in particolare di quella nazionale, alle figure dell'Antichità. La "tragedia storica" di Legouvet ne è un esempio. Non c'è dunque da stupirsi che Stendhal nel suo celebre Racine et Shakespeare raccomandi ai drammaturgi di consacrarsi alla creazione di tragedie nazionali in prosa. Voltaire userà questo mezzo per inviare dei messaggi al pubblico contemporaneo. "Classica" o "nazionale", la tragedia diventa un'arma di propaganda o di contestazione pubblica. Nel periodo della Restaurazione Talma utilizzerà i suoi ruoli tragici per esaltare i ricordi dell'Impero e sfidare il potere dei Borboni. È in fondo quello che si erano proposti Hugo e Dumas nelle loro tragedie. Gérard de Nerval, che aveva fatto parte della "camarilla" dei giovani romantici del febbraio 1830, farà osservare, 15 anni più tardi, che la riforma romantica (parla di "riforma" e non di "rivoluzione") era stata prevista e incoraggiata da Voltaire. «Qu'on n'oublie pas que - scriverà nella «Presse» (28 juillet 1845) - tout en se rattachant aux traditions du Grand Siècle, Voltaire poursuivait et annonçait lui-même un progrès que Victor Hugo et Alexandre Dumas ont noblement évité d'accomplir».

7 La prova che "tragedia storica" e "dramma romantico" avessero delle analogie, sta nel fatto che ambedue sparirono insieme alla metà del secolo.

8 Sainte-Beuve, con la sua acuta intuizione critica, si era proposto di rivalutare $\mathrm{i}$ drammaturgi che avevano preceduto i romantici, documentandosi sui giornali del primo Ottocento.

9 Nel suo discorso di ammissione alla Accademia di Francia (27 febbraio 1845) fu costretto a commemorare Casimir Delavigne, del quale aveva occupato il posto, alla presenza di Victor Hugo, direttore dell'Accademia. Con coraggio e una certa diplomazia, sostenne che «la manière de Delavigne au théâtre consiste bien en une sorte de tragique "perfectionné" qui concilierait le modèle racinien et la modernité. C'est-à-dire l'histoire». La "rivoluzione" di Hugo viene così ridimensionata.

10 Nel gennaio 1841 Sainte-Beuve aveva già messo in evidenza che nelle opere del drammaturgo Pierre Lebrun vi erano già delle allusioni alla storia contemporanea (Ulysse del 1814, Marie Stuart del 1820). Lo stesso Lebrun aveva fatto rappresentare al Théâtre-Français (1 marzo 1825) un dramma: il Cid d'Andalousie, che non era sfuggito alla censura per un'ardita scena d'amore, causa della sospensione delle rappresentazioni. Proprio Chateaubriand aveva aiutato Lebrun a far sospendere il veto!

11 Purtroppo, per varie circostanze (indisposizione e morte di attori, isolamento dell'autore), quest'opera fu dimenticata. Eppure Lebrun era stato un innovatore, per il 
suo stile molto naturale e per l'argomento scelto, caro al pubblico che amava il patetico naturale.

12 Victor Hugo, più abile, cinque anni più tardi, con Hernani cercherà di ampliare e diffondere il successo ottenuto con il suo Cid, per cancellare tutti i tentativi di rinnovamento precedenti.

13 Sainte-Beuve si chiede quanto sia proficuo per un autore far parte di un gruppo importante per mettere in evidenza il valore delle sue opere, e riconosce che la partecipazione al Cénacle romantico aveva favorito lo sviluppo della fama dei "grandi" romantici, lasciando gli altri nell'ombra.

14 Il dovere del critico è proprio quello di fare uscire dall'ombra i drammaturgi degli anni 1820-1830 che non avevano saputo approfittare dell'“effet Cénacle".

15 Inutile dire quanto questo articolo del noto specialista di Gérard de Nerval sia utile per ridimensionare il giudizio della critica sull'affermazione del teatro romantico in Francia e per restituire ad alcuni autori del primo Ottocento, considerati "classici", la priorità sulla "rivoluzione" così abilmente sostenuta e divulgata dai suoi rappresentanti. 